\title{
INTEGRAÇÃO DOS PILARES DA SUSTENTABILIDADE EM PROJETOS INTEGRADORES NO CURSO DE ENGENHARIA DE PRODUÇÃO
}

\author{
PANORAMA INTEGRATION OF THE SUSTAINABILITY PILLARS IN INTEGRATING \\ PROJECTS IN THE PRODUCTION ENGINEERING COURSE
}

Thiago Shoji Obi Tamachiro ${ }^{1}$, Alexandre Maneira dos Santos ${ }^{2}$

DOI: 10.37702/REE2236-0158.v40p95-101.2021

\section{RESUMO}

Projetos integradores são vistos como uma ótima ferramenta para o ensino de assuntos relacionados à formação de um engenheiro de produção. Desse modo, este artigo tem o objetivo de apresentar um Projeto Integrador, realizado em uma instituição de ensino superior da cidade de Curitiba-PR, envolvendo os pilares da sustentabilidade. O projeto, composto por alunos dos cursos de Engenharia de Produção, Design e Publicidade e Propaganda, foi dividido em duas etapas. Na primeira etapa foi proposto aos alunos o desafio de produzir sabão em pedra a partir da reutilização de óleo de fritura; na segunda etapa o desafio de atuar na concepção, pesquisa, planejamento, desenvolvimento e produção de produtos de Higiene Pessoal, Perfumaria e Cosméticos (HPPC). A realização deste trabalho promoveu a inserção de assuntos como planejamento e produção do produto e da embalagem, identificação de nicho de mercado e elaboração do conceito do produto. Os pilares da sustentabilidade também fizeram parte desta prática, na qual o aspecto ambiental foi atrelado ao reaproveitamento de matéria-prima, ao lado econômico explorado na gestão de recursos a fim de tornar a operação viável economicamente, ao estímulo da mentalidade empreendedora e ao meio social, ao se realizar a doação do produto gerado para instituições de caridade.

Palavras-chave: Projeto Integrador; produção de sabão; cosméticos; pilares da sustentabilidade.

\begin{abstract}
Integrating projects are seen as a great tool for teaching subjects related to the formation of a Production Engineer. Thus, this article aims to present an integrative project, carried out in a higher education institution in the city of Curitiba-PR, involving the pillars of sustainability. The project, composed of students from the Production Engineering, Design and Advertising and Marketing courses, was divided into two stages, in the first stage the students were encouraged to produce bar soap from the reuse of frying oil, and in the second stage, the challenge was to promote the design, research, planning, development and production of Personal Hygiene, Perfumery and Cosmetics (HPPC) products. The accomplishment of this work allowed the insertion of subjects such as product and packaging planning and production, identification of market niche and elaboration of the product concept. The pillars of sustainability were also part of this practice, where the environmental aspect was linked to the reuse of raw materials, the economic side explored in resource management in order to make the operation economically viable and to stimulate the entrepreneurial mindset, and the social environment, by donating the products to charities.
\end{abstract}

Keywords: Integrating Projects; soap production; cosmetics; pillars of sustainability.

\footnotetext{
${ }^{1}$ Mestrando, bolsista CAPES, no Programa de Pós-Graduação em Engenharia de Produção, Universidade Federal do Paraná (UFPR) - Curitiba; thiagotamachiro@gmail.com

${ }^{2}$ Mestre em Engenharia Mecânica pelo Programa de Pós-Graduação em Engenharia Mecânica, Universidade Federal do Paraná (UFPR) - Curitiba. Professor da FAE, Centro Universitário - Curitiba; alexandre.santos@fae.edu
} 


\section{INTRODUÇÃO}

Um Projeto Integrador (PI) consiste na realização de um projeto acadêmico que integra mais de uma disciplina, professores e áreas de conhecimento (MORAN, 2013). O Projeto Integrador, além de relacionar as disciplinas, possibilita que os alunos se sintam desafiados em resolver problemas simulados ou reais que envolvam a sua formação profissional (FERLIN; OLIANI, 2014). Essa abordagem proporciona, para os alunos, um sentido muito mais profundo no aprendizado, não apenas por conhecer a realidade do mercado de trabalho, mas também por trazer soluções concretas para a comunidade (MORAN, 2013). Além disso, Santos e Barra (2012) afirmam que a realização de Projetos Integradores apresenta inúmeras vantagens aos alunos, por exemplo o desenvolvimento da capacidade de pesquisa, da tomada de decisão e de trabalhar em equipes multidisciplinares.

Um tema atual e que é interessante de se tratar em projetos integradores é o da sustentabilidade, pois estimula os alunos a desenvolver soluções pensando nas três dimensões da sustentabilidade: ambiental, econômica e social.

Nesse sentido este artigo tem como objetivo apresentar um Projeto Integrador, realizado em uma Instituição de Ensino Superior (IES) privada da cidade de CuritibaPR, envolvendo os três pilares da sustentabilidade. $\mathrm{O}$ Projeto Integrador, composto por alunos dos cursos de Engenharia de Produção, Design e Publicidade e Propaganda, teve como objetivo a produção de sabão em pedra a partir da reutilização de óleo de fritura e o desenvolvimento de um produto de Higiene Pessoal, Perfumaria e Cosmético (HPPC).

\section{OS PILARES DA SUSTENTABILIDADE}

A sustentabilidade pode ser definida como a capacidade de um sistema, seja humano, natural ou misto, de resistir ou se adaptar às mudanças de forças endógenas ou exógenas por tempo indeterminado (DOVERS; HANDMER, 1992). Segundo Elkington (1994), para que a sustentabilidade aconteça, é necessário o atendimento das dimensões econômica, social e ambiental, que também são conhecidas internacionalmente como Triple Bottom Line (TBL).

O TBL foi criado para que as empresas sejam estimuladas a basear suas decisões estratégicas nessas dimensões. A sustentabilidade econômica do negócio acontece ao se gerenciar empresas lucrativas e geradoras de valor; a sustentabilidade social é alcançada por meio do estímulo de atividades de entretenimento e justiça social para a comunidade na qual a empresa está inserida; e, tudo isso, mantendo-se o cuidado com o meio ambiente, por meio de programas de reciclagem e preservação (PAZ; KIPPER, 2016). Nesse sentido, em um contexto organizacional, a sustentabilidade pode ser vista como uma melhoria no crescimento financeiro, reduzindo os impactos ambientais negativos e atendendo às expectativas da sociedade (SILVEIRA, 2013).

A Figura 1 ilustra o tripé da sustentabilidade, indicando que o TBL também pode mensurar as inter-relações entre as dimensões do desenvolvimento sustentável: eco ambiental, eco social, socioambiental e eco socioambiental.

\section{Figura 1 - O Tripé da Sustentabilidade}

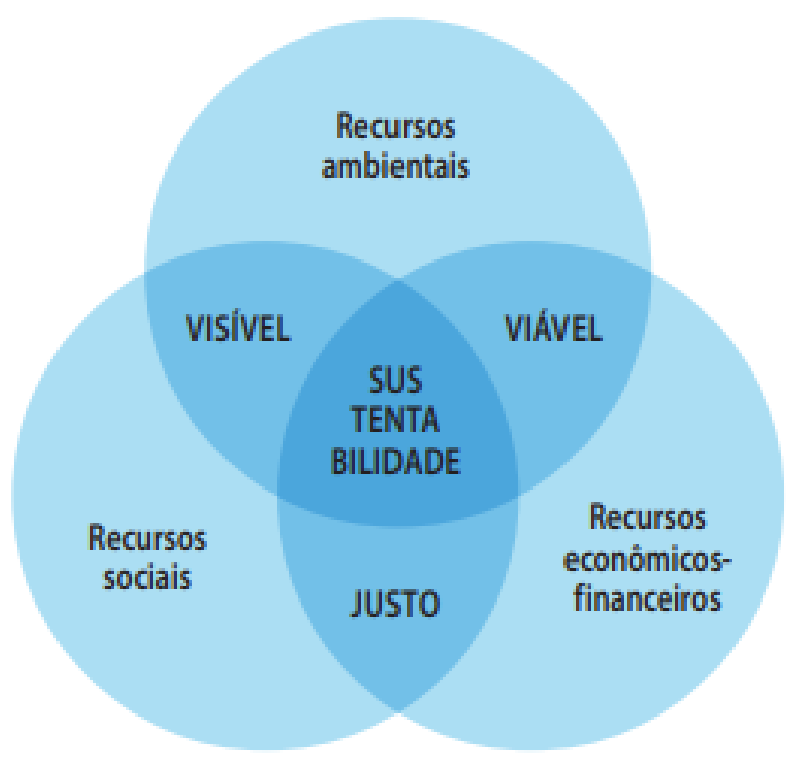

Fonte: Alledi (2003). 


\section{DESENVOLVIMENTO DO PROJETO INTEGRADOR}

O Projeto Integrador em questão foi dividido em duas etapas: a produção de sabão em pedra, a partir da utilização de óleo de cozinha usado e Hidróxido de Sódio $(\mathrm{NaOH})$, e o desenvolvimento de um produto HPPC.

Embora cada curso fosse orientado para contribuir de forma mais significativa em uma parte específica do projeto, o conceito do Projeto Integrador demanda que haja uma grande integração entre os alunos, promovendo o aprendizado coletivo, independente da atividade a ser desenvolvida.

A segmentação do Projeto Integrador em duas etapas visa a dar maior abrangência possível no processo de aprendizagem, contemplando desde as habilidades técnicas (hard skills), evidenciadas nos conteúdos programáticos das disciplinas dos respectivos cursos, até as habilidades comportamentais (soft skills), que transcendem a sala de aula e promovem um estímulo adicional em direção ao trabalho em equipe, à comunicação e ao gerenciamento de conflitos.

Nesse contexto, a etapa um - constituída pela produção do sabão - configura um trabalho mais técnico em que o planejamento e a visão lógica devem prevalecer. Tal atividade é composta por uma reação química na qual os parâmetros de processo e as decisões das equipes são fundamentais para o sucesso ou o fracasso da atividade. Já na etapa dois formada pela produção dos produtos de HPPC -, a criatividade e o compromisso com a sustentabilidade tornam esse momento mais lúdico e estimulante, sem perder o lado desafiador e competitivo que uma atividade dessa natureza pode oferecer.

Dessa forma, a complementariedade das duas etapas resulta em um processo de certa complexidade e de alta relevância no processo de ensino e aprendizagem. Um detalhamento de cada uma das duas etapas é apresentado na sequência.

\section{Produção de sabão}

A partir de uma fórmula padrão proposta, os alunos tiveram que adequar as quantidades utilizadas no processo com o conceito do produto proposto gerando um produto mais ou menos suave, de acordo com o conceito. Também foi permitido trabalhar com outras características do produto, tais como a sua coloração através da introdução de pigmentos e/ou fragrâncias. A apresentação final do projeto foi contemplada pela apresentação física do produto dentro da sua embalagem e o desenvolvimento de um site que ilustrasse o detalhamento do processo produtivo e o conceito/apresentação do produto final.

Coube inicialmente aos alunos do curso de Engenharia de Produção todo o acompanhamento do processo químico, incluindo os fluxogramas, custos envolvidos e parâmetros de controle do processo. Os alunos do curso de Design trabalharam com o conceito do produto e concepção, desenvolvimento e fabricação das embalagens. Por sua vez, os alunos de Publicidade e Propaganda focaram nas questões mercadológicas, registros fotográficos das atividades e criação de site para comercialização do produto.

Todas as etapas do processo foram registradas e avaliadas segundo os fundamentos das suas respectivas disciplinas. No curso de Engenharia de Produção, por exemplo, foram avaliados os fluxogramas, as planilhas de acompanhamento do processo e de eficiência de produção. A definição do conceito do produto, matriz SWOT e criação da embalagem foram avaliadas com maior relevância no curso de Design. Ao curso de Publicidade e Propaganda coube a criação do site e registros fotográficos do processo de fabricação e do produto final que também foram avaliados.

\section{Desenvolvimento de produto de Higiene Pessoal, Perfumaria e Cosméticos}

Após a finalização da etapa mais técnica do projeto integrador, foi iniciada a segunda etapa, na qual os alunos puderam complementar os seus conhecimentos técnicos com abordagens mais criativas, sem deixar de lado o aspecto 
mercadológico e comercial do produto. O objetivo dessa atividade foi atuar na concepção, pesquisa, planejamento, desenvolvimento e produção de produtos de Higiene Pessoal, Perfumaria e Cosméticos (HPPC). O produto escolhido pelo grupo deveria fazer parte de uma das famílias de produtos básicos de HPPC definidas na proposta inicial da atividade, que são: hidratante de pele ou cabelo, perfume, creme de barbear ou shampoo para diversos tipos de cabelo.

Cada grupo deveria escolher o seu produto e buscar a fórmula que melhor atendesse ao conceito definido previamente pelo grupo. Alguns sites de produção de cosméticos foram sugeridos pelos professores do projeto para que os alunos pudessem encontrar uma formulação que pudesse corresponder ao conceito do produto definido pelo grupo. Para essa etapa do projeto ficou definido que, além da concepção e produção do produto, os alunos deveriam também expor os seus produtos em um ponto de venda.

Nesse contexto, as atividades de cada equipe foram divididas da seguinte forma: alunos do curso de Engenharia de Produção fiaram responsáveis pela elaboração do produto escolhido e cálculo do custo total do lote a ser processado; os alunos de Design trabalharam na criação do conceito do produto e análise de mercado; por último, os alunos do curso de Publicidade e Propaganda ficaram encarregados da organização do evento para a demonstração dos produtos desenvolvidos.

\section{RESULTADOS E DISCUSSÕES}

Nesta secção serão apresentados os resultados das duas etapas do projeto integrador.

\section{Resultados da produção de sabão}

A etapa inicial da atividade compreendeu a criação do conceito do produto, a identificação do nicho de mercado, a concepção da embalagem e, sobretudo, a reflexão sobre o aspecto da sustentabilidade do produto, considerando como ideia central a utilização de óleo de cozinha como matéria-prima fundamental para a produção do sabão. Como destino final da produção, ficou definida a doação do material para entidades públicas ou privadas que pudessem fazer o bom uso do sabão. A fase de planejamento, embora essencial em qualquer projeto, acaba sendo de alguma forma deixada de lado por algumas equipes que, com a ânsia de já produzir o sabão, não enxergam a sua relevância no contexto final do projeto.

Com a fase de planejamento concluída, as equipes passaram a se organizar para a produção do sabão e da sua embalagem. Nessa hora, tornou-se perceptível a distinção entre aquelas equipes que conseguiram se planejar com afinco e realizar as atividades práticas com muito mais rapidez e assertividade e aquelas que não conseguiram realizar um bom planejamento. A Figura 2 ilustra $\mathrm{o}$ detalhamento de algumas atividades executadas nessa fase.

Figura 2 - Controle do processo e fabricação do sabão

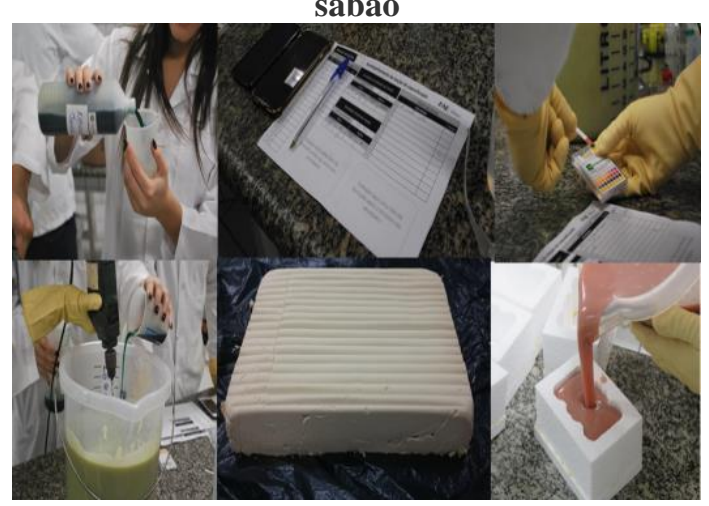

Fonte: acervo dos autores (2020).

Na medida em que o sabão vai reagindo e secando, a ponto de ser extraído da forma, os alunos se prepararam para a confecção das embalagens e planejamento dos ensaios fotográficos para divulgação dos seus produtos. Nessa fase, os alunos de publicidade e propaganda se depararam com uma situação real na qual o produto e a embalagem já concebidos têm que ser expostos da melhor forma possível e de acordo com o conceito previamente estabelecido. Esses registros também são fundamentais para a criação do site. Algumas ilustrações sobre os ensaios fotográficos do produto são contempladas abaixo na Figura 3. 
Figura 3 - Apresentação do produto

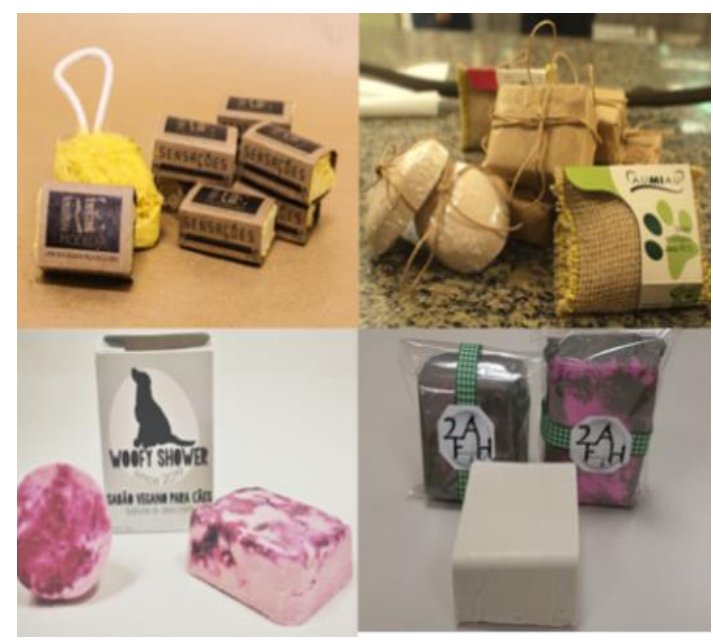

Fonte: acervo dos autores (2020).

Após as etapas de produção, divulgação do produto e desenvolvimento do site, realizou-se um evento no qual as equipes que conseguiram realizar suas atividades de forma majestosa pudessem ser recompensadas. O evento contou com a participação dos alunos que puderam expor o produto final do seu trabalho para um público votante. O público teve a missão de avaliar detalhadamente algumas características, como relevância do conceito, apresentação do produto, site mais interessante, entre outros aspectos. Cada pessoa que participou do processo de votação ganhou uma amostra dos produtos que estavam em exposição.

Esse evento foi extremamente gratificante para todos que apoiaram o projeto, pois a exposição gerou muitos feedbacks positivos para os alunos e professores envolvidos. Em especial para os alunos, foi um momento de aprendizado que transcendeu os limites da sala de aula; isso sem considerar a grande oportunidade de realizar trabalho em equipe envolvendo diversos cursos do meio universitário.

Com a compilação dos votos dos 81 participantes da exposição, foi organizado um evento final para divulgação dos resultados e confraternização final. Nesse momento foi nomeada também a instituição que seria agraciada com o produto final do projeto.

Com a produção final de aproximadamente $50 \mathrm{~kg}$ de sabão, deu-se a entrega do material para a entidade escolhida por um time formado pelos próprios alunos. Além da distribuição, outros cuidados foram tomados para que o material fosse consumido com a devida prudência, pois embora acondicionado em embalagens atraentes, o sabão produzido a partir do hidróxido de sódio concentrado apresenta alto teor de alcalinidade, o que é contraindicado para pessoas que têm pele sensível e altamente contraindicado para higiene pessoal.

\section{Resultados do desenvolvimento de produtos HPPC}

$\mathrm{Na}$ segunda etapa do projeto integrador os alunos tiveram a oportunidade de interagir com o consumidor final dos produtos de HPPC através da criação e desenvolvimento do ponto de venda. Para que houvesse a divulgação dos produtos, foi destinada uma área da faculdade para que os alunos pudessem expor os seus produtos por um período de quatro horas. Essa área foi dividida entre os grupos que tiveram como desafio fazer o planejamento adequado do ponto de venda (PDV), utilizando displays, expositores promocionais e demais recursos explorados nos cursos de Design e Publicidade e Propaganda. Toda a elaboração e construção dos elementos de divulgação do PDV foram feitas pelos próprios alunos. Após a montagem de toda a estrutura, alunos, professores e funcionários da instituição puderam participar da exposição, conhecer cada um dos produtos apresentados e contribuir com suas percepções. Para os alunos expositores foi um momento muito gratificante em razão da possibilidade de compreensão da cadeia de suprimentos que envolveu esse processo, desde 0 desenvolvimento e busca das matérias-primas com seus respectivos fornecedores, passando pela fase de produção efetiva do produto e sua embalagem, até a finalização do processo no ponto de venda, com a interação e as expectativas do cliente final. A Figura 4 ilustra o ponto de venda de algumas equipes com seus respectivos produtos em exposição. 
Figura 4 - Exposição dos produtos

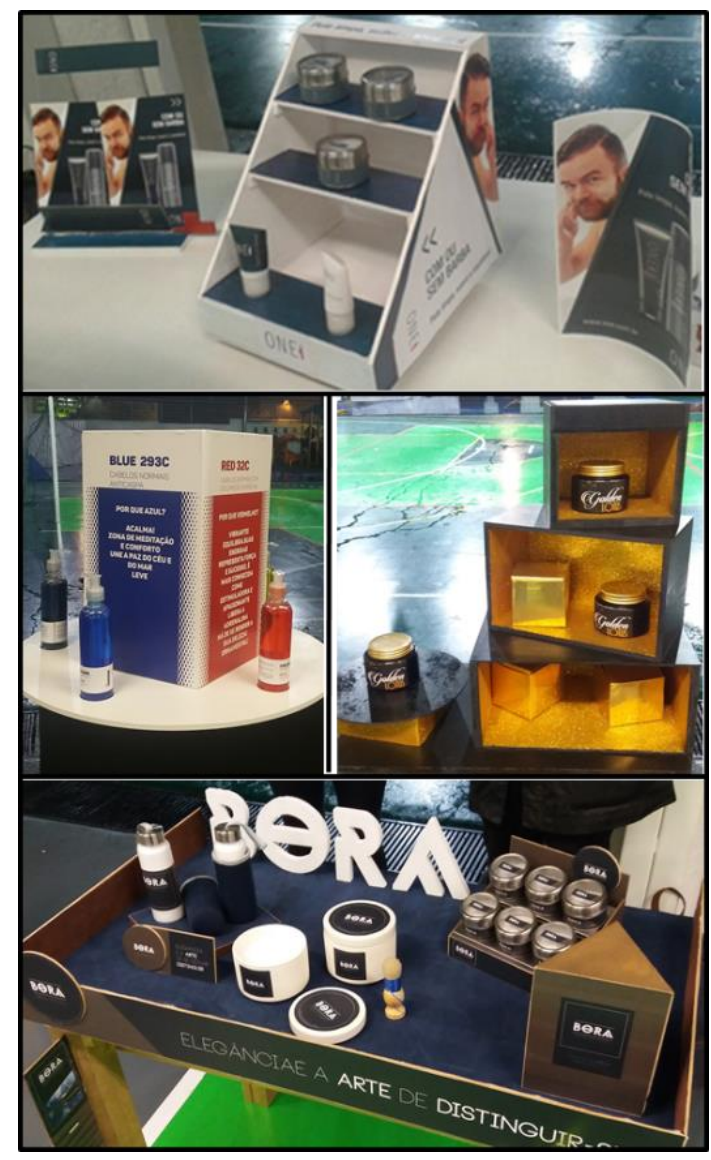

Fonte: acervo dos autores (2020).

Como houve a flexibilização para que os alunos pudessem escolher entre algumas linhas de produtos (hidratante de pele ou cabelo, perfume, creme de barbear ou shampoo para diversos tipos de cabelo), a exposição ficou bastante diversificada e atraente para os que puderam participar do evento. Entre as equipes envolvidas no projeto, destacaram-se alguns produtos direcionados para o público masculino, tais como um creme de barbear feito a partir do sabão produzido na primeira etapa do projeto integrador, além de uma linha completa de sabão e shampoo voltados para o mercado de pets.

\section{CONSIDERAÇÕES FINAIS}

A consolidação deste trabalho envolveu claramente a essência da sustentabilidade nos seus princípios. A possibilidade de reaproveitar uma matéria-prima - que em condições normais serviria apenas para ser descartada no ambiente - trouxe, além do aprendizado técnico-científico, uma grande reflexão sobre os aspectos ambientais da sustentabilidade, considerando inclusive que o mesmo óleo empregado nessa prática para produzir sabão pode causar severos danos ao meio ambiente quando mal destinado e em contato com rios e lençóis freáticos. Ainda no pilar da sustentabilidade, verificou-se a possibilidade de utilização do sabão produzido como insumo para a produção de um creme de barbear; portanto, testes iniciais deverão ser realizados quanto à segurança do uso do produto sob a pele do usuário.

Os recursos econômicos e financeiros foram explorados intensamente no levantamento dos custos envolvidos nesse processo e na gestão dos recursos a fim de tornar a operação viável economicamente. Também foi observado o estímulo ao pensamento empreendedor, visto que alguns alunos pensaram na ideia de abrir um negócio relacionado aos produtos que foram desenvolvidos ao longo do projeto.

Ainda complementando o tripé da sustentabilidade, a doação do produto gerado nessa prática para instituições de caridade fomenta a necessidade de se fazer algo pelo próximo, o que, muitas vezes, não é tão perceptível por alguns alunos do curso superior. De forma geral, as experiências vivenciadas foram positivas e certamente serão lembradas pelos que dela participaram.

Entretanto, enquanto processo evolutivo, vale pontuar a necessidade de um perfeito alinhamento entre todos os cursos participantes no sentido de harmonizar os conteúdos programáticos de cada disciplina e administrar os conflitos iminentes entre os acadêmicos de cursos com abrangências e características diferentes entre si.

\section{AGRADECIMENTOS}

O presente trabalho foi realizado com apoio da Coordenação de Aperfeiçoamento de Pessoal de Nível Superior - Brasil (CAPES) Código de Financiamento 001. 


\section{REFERÊNCIAS}

ALLEDI, C. F. O tripé da sustentabilidade. 2003. Trabalho de Conclusão do Curso (Gestão de Negócios Sustentáveis) - LATEC-UFF Business School, Rio de Janeiro, 2003.

DOVERS, S. R.; HANDMER, J. W. Uncertainty, sustainability and change. Global Environmental Change, v. 2, n. 4, p. 262-276, 1992.

ELKINGTON, J. Triple bottom line revolution: reporting for the third millennium. Australian CPA, v. 69, p. 75, 1994.

FERLIN, E. P.; OLIANI, D. A disciplina de Projeto Integrador como elemento norteador do processo ensinoaprendizagem: a experiência do curso de Engenharia da Computação. COBENGE: Minas Gerais, 2014.

MORAN, J. Metodologias ativas para uma aprendizagem mais profunda. Educação

Transformadora. 2013. Disponível em: http://www2.eca.usp.br/moran/wpcontent/uploads/2013/12/metodologias _moran1.pdf. Acesso em: 28 jun. 2019.

PAZ, F. J.; KIPPER, L. M. Sustentabilidade nas organizações: vantagens e desafios. GEPROS. Gestão da Produção, Operações e Sistemas, Bauru, v. 11, n. 2, p. 85-102, abr-jun. 2016.

SANTOS, M. C. C.; BARRA, S. R. O Projeto Integrador como ferramenta de construção de habilidades e competências no Ensino de Engenharia e Tecnologia. COBENGE: Pará, 2012.

SILVEIRA, M. A. Strategic management of innovation towards sustainable development of brazilian electronic. Journal Technologic Management \& Innovation, v. 8, s/n, p. 174-186, 2013.

\section{DADOS BIOGRÁFICOS DOS AUTORES}

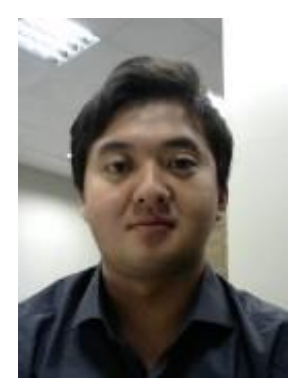

Thiago Shoji Obi Tamachiro - Mestrando em Engenharia de Produção, linha de pesquisa: inovação em projetos, produtos e processos, pela Universidade Federal do Paraná. Especializando em Gestão de Operações - Six Sigma Black Belt pela FAE Business School com formação complementar em Consultoria Organizacional. Graduação em Engenharia de Produção pela FAE Centro Universitário (2018). Agraciado com o Prêmio Francisco de Assis - Melhor aluno do curso de Engenharia de Produção.

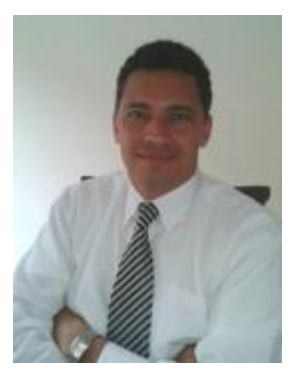

Alexandre Maneira dos Santos - Graduação em Engenharia Química pela Universidade de São Paulo com MBA em Gestão Empresarial pela Fundação Getúlio Vargas e Mestrado em Engenharia Mecânica - área de Manufatura pela Universidade Federal do Paraná. Mais de vinte anos atuando nas áreas de qualidade, produção, logística, engenharia de processos e operações industriais em indústrias multinacionais como Renner Dupont, Volkswagen e Electrolux. 